\title{
Proteomic Study of Retinal Proteins Associated with Transcorneal Electric Stimulation in Rats
}

\author{
Takashi Kanamoto, ${ }^{1}$ Nazariy Souchelnytskyi, ${ }^{2}$ Takuji Kurimoto, ${ }^{3}$ Yasuhiro Ikeda, ${ }^{4}$ \\ Hiroaki Sakaue, ${ }^{5}$ Yasunari Munemasa, ${ }^{6}$ and Yoshiaki Kiuchi ${ }^{7}$ \\ ${ }^{1}$ Department of Ophtahlomology, Hiroshima Memorial Hospital, 1-4-3 Honkawacho, Minami-ku, Hiroshima 730-0802, Japan \\ ${ }^{2}$ Personalized Cancer Medicine Unit, Department of Oncology-Pathology, Karolinska Institute, 17177 Stockholm, Sweden \\ ${ }^{3}$ Department of Ophthalmology, Osaka Medical College, 2-7 Daigaku-cho, Takatsuki-shi, Osaka 569-8686, Japan \\ ${ }^{4}$ Department of Ophthalmology, Kyushu University, 3-1-1 Maedashi, Higashi-ku, Fukuoka 812-8592, Japan \\ ${ }^{5}$ Department of Pharmaceutical Sciences, International University of Health and Welfare, 2600-1 Kitakanemaru, \\ Tahara-shi, Tochigi 324-8501, Japan \\ ${ }^{6}$ Department of Ophthalmology, St. Marianna Medical College, 2-16-1 Sugao, Miyamae-ku, Kawasaki-shi, Kanagawa 216-8511, Japan \\ ${ }^{7}$ Department of Ophthalmology and Visual Sciences, Hiroshima University, 1-2-3 Kasumi, Minami-ku, Hiroshiam 734-8551, Japan
}

Correspondence should be addressed to Takashi Kanamoto; tkana@hiroshima-u.ac.jp

Received 21 December 2014; Revised 19 February 2015; Accepted 19 February 2015

Academic Editor: Biju B. Thomas

Copyright (C) 2015 Takashi Kanamoto et al. This is an open access article distributed under the Creative Commons Attribution License, which permits unrestricted use, distribution, and reproduction in any medium, provided the original work is properly cited.

\begin{abstract}
Background. To investigate how transcorneal electric stimulation (TES) affects the retina, by identifying those proteins up- and downregulated by transcorneal electric stimulation (TES) in the retina of rats. Methods. Adult Wistar rats received TES on the left eyes at different electrical currents while the right eyes received no treatment and served as controls. After TES, the eye was enucleated and the retina was isolated. The retinas were analyzed by proteomics. Results. Proteomics showed that twenty-five proteins were upregulated by TES. The identified proteins included cellular signaling proteins, proteins associated with neuronal transmission, metabolic proteins, immunological factors, and structural proteins. Conclusions. TES induced changes in expression of various functional proteins in the retina.
\end{abstract}

\section{Background}

Electrical stimulation has been shown to enhance the regeneration of axons after surgical transaction of the femoral nerve in adult rats [1] and accelerate the speed of femoral motor axonal regeneration [2]. Thus, electrical stimulation can have regenerative effects on damaged peripheral nerves.

Transcorneal electrical stimulation (TES) has been tried on adult rats and human patients. In an animal model of retinitis pigmentosa, TES prolonged the survival of photoreceptors morphologically and delayed the decrease of retinal function by electrophysiological analysis [3]. TES also promoted the survival of retinal ganglion cells (RGCs) of rats after optic nerve injury [4]. Furthermore, the results of TES in cat eyes suggested that TES activated retinal neurons through vascular changes [5].
In its clinical aspects, TES has been found to improve the visual acuity and peripheral visual field in patients with traumatic optic neuropathy [6], and its single-time application to eyes with nonarteritic ischemic optic neuropathy (NAION) improved the subject's visual acuity and peripheral visual field [6]. It was reported that TES improved the visual acuity and visual fields in three patients with longstanding retinal artery occlusion [7] and that TES improved the visual field in eyes with branch retinal artery occlusion [8]. In addition, TES also improved the inner retinal function in patients with retinal degeneration, including retinal pigmentosa and cone-rod dystrophy [9], and also improved visual acuity in patients with vitelliform macular dystrophy [10]. Thus, TES has been proven to be beneficial for retinal neuronal diseases, including retinal vascular diseases and retinal degeneration, in clinical trials. 
The mechanism by which TES alters the retinal neurons to lead to good outcomes has not been determined, however. This information is essential for justifying the use of TES to treat not only ischemic retinal diseases but also other types of retinal diseases. Retinal function is mediated by neural proteins, and neural proteins themselves are regulated by cellular protein signaling networks. So, we hypothesized that a proteomic analysis of the expression patterns of proteins induced by TES will provide evidence regarding the mechanism of retinal regeneration. Identification by proteomics of those proteins affected by TES would also have value for its own sake. We found that the expressions of 25 proteins were up- or downregulated after TES.

\section{Methods}

2.1. Animals. All experiments were performed in accordance with the principles of the Association for Research in Vision and Ophthalmology for the use of animals in ophthalmic research. The procedures used in these experiments were approved by the Animal Use Committee of Hiroshima University.

Adult Wistar rats were obtained from CLEA (Tokyo, Japan) and were housed in clear plastic cages containing pine bedding. The animal quarters were kept at $21^{\circ} \mathrm{C}$ on a $12 \mathrm{hr}: 12 \mathrm{hr}$ light : dark cycle.

2.2. Transcorneal Electrical Stimulation (TES). The rats were anesthetized intraperitoneally with chloral hydrate. Only the left eye was electrically stimulated while the right eyes received no stimulation and served as the controls. For the stimulation, the cornea was anesthetized with a drop of $0.4 \%$ oxybuprocaine $\mathrm{HCl}$, and a contact lens electrode with inner and outer circular concentric electrodes was placed on the cornea with a drop of $2.5 \%$ methylcellulose to maintain good electrical contact and prevent corneal dehydration. Biphasic rectangular (1 ms phase duration) current pulses were delivered at a frequency of $20 \mathrm{~Hz}$ from an electrical stimulation system (stimulator: SEN-8203, Nihon Kohden, Tokyo, Japan; isolator: A365, World Precision Instruments, Sarasota, FL) through the contact lens electrodes. The frequency was $20 \mathrm{~Hz}$ and the duration of the stimulation was 30 minutes, which had already been shown to be an appropriate time for stimulation [11]. The current intensity was varied at $50 \mu \mathrm{A}$, $100 \mu \mathrm{A}$, and $200 \mu \mathrm{A}$. Only one session of TES was given, and the eyes were enucleated 30 minutes or 24 hours after the TES. Three rats were prepared in each group and, totally, eighteen rats were studied.

2.3. Two-Dimensional Electrophoresis and Gel Analysis. Rats were deeply anesthetized with chloral hydrate and the eyes were enucleated. The retinas from stimulated and nonstimulated eyes were carefully isolated in PBS and solubilized in sample buffer (8 M urea, 4\% CHAPS, 0.5\% DTT, IPG buffer, and $\mathrm{pH} 3-10)$. The protein concentration of lysatewas measured with the Bradford assay.

Two-dimensional electrophoresis and protein identification were performed as described in detail [12]. Isoelectrofocusing was performed on strips ( $\mathrm{pH}$ 3-10 nonlinear gradient,
$18 \mathrm{~cm}$, GE Healthcare, Buckinghamshire, UK). The firstdimension isoelectrophoresis was performed in IPGphor (GE Healthcare) according to the manufacturer's instructions. After the isoelectric focusing, the strips were placed in equilibration buffer-1 (50 mM Tris- $\mathrm{HCl}, \mathrm{pH}$ 8.8, 6.0 M urea, 2.0\% SDS, 30\% glycerol, and 1\% DTT) and then in equilibration buffer-2 (50 mM Tris-HCl, pH 8.8, 6.0 M urea, 2.0\% SDS, $30 \%$ glycerol, and $4 \%$ iodoacetamide). The equilibrated strips were loaded onto SDS-containing $10 \%$ polyacrylamide gel, and SDS-PAGE was performed. After the electrophoresis, the gels were fixed in 7.5\% acetic acid and 20\% methanol and sensitized in $25 \%$ ethanol, $0.2 \%$ sodium thiosulfate, and $3.4 \%$ sodium acetate. The gels were stained with $0.25 \%$ silver nitrate and developed with $2.5 \%$ sodium carbonate and $0.04 \%$ formaldehyde. Silver-stained gels were scanned by an image scanner (ES-2200, EPSON, Tokyo, Japan), and the volume of spots was determined with PD-Quest software (Bio-Rad Laboratories, Hercules, CA, USA) following the manufacturer's instructions. The values of the volume of each matched spot on the master gels were compared. Spots with differences in expression were then identified by mass spectrometry.

2.4. Protein Identification. The stained protein-containing spots were destained with $30 \mathrm{mM}$ potassium ferricyanide and $100 \mathrm{mM}$ sodium thiosulfate. Then, the gel pieces were dipped in $0.1 \mathrm{M}$ sodium hydrocarbonate and washed with acetonitrile. After drying, in-gel digestion was performed with trypsin. Then, $0.1 \%$ trifluoroacetic acid (TFA) and 10\% acetonitrile in water were used to extract the peptides, and the extract was desalted on a nanocolumn. After washing the column with $0.1 \%$ TFA in water, the matrix was eluted with acetonitrile containing alpha-cyano-4-hydroxycinnamic acid directly onto the MALDI target. Spectra were generated on a MALDI-TOF mass spectrometer (Bruker Daltonics, Billerica, MA, USA). The spectra were internally calibrated using known internal tryptic autodigestion peptides and searches were made in the NCBI database using Profound.

\section{Results}

3.1. Two-Dimensional Proteomic Maps of Rat Retinas after TES. To identify the proteins expressed after TES, we compared the proteomes in TES-stimulated and nonstimulated rat retinas. The total lysates of the retina at each current intensity $(50 \mu \mathrm{A}, 100 \mu \mathrm{A}$, and $200 \mu \mathrm{A})$ and post-TES times (30 minutes and 24 hours after TES) were resolved by twodimensional gel electrophoresis.

We detected approximately seven hundred protein spots on the two-dimensional gels after silver staining. The volume of each protein spot was quantified by PD-Quest software, and the largest volume observed was 41,964 units. We analyzed three gels for each current intensity and post-TES time to ensure the repeatability of the protein volume measure. Thirty-seven protein spots, which were not detected without TES, remained as inducible expression by TES, and we could not see the protein spots whose volume decreased after TES. In addition, the pattern of expression changed between $30 \mathrm{~min}$ and $24 \mathrm{~h}$ after TES. We also performed a manual 


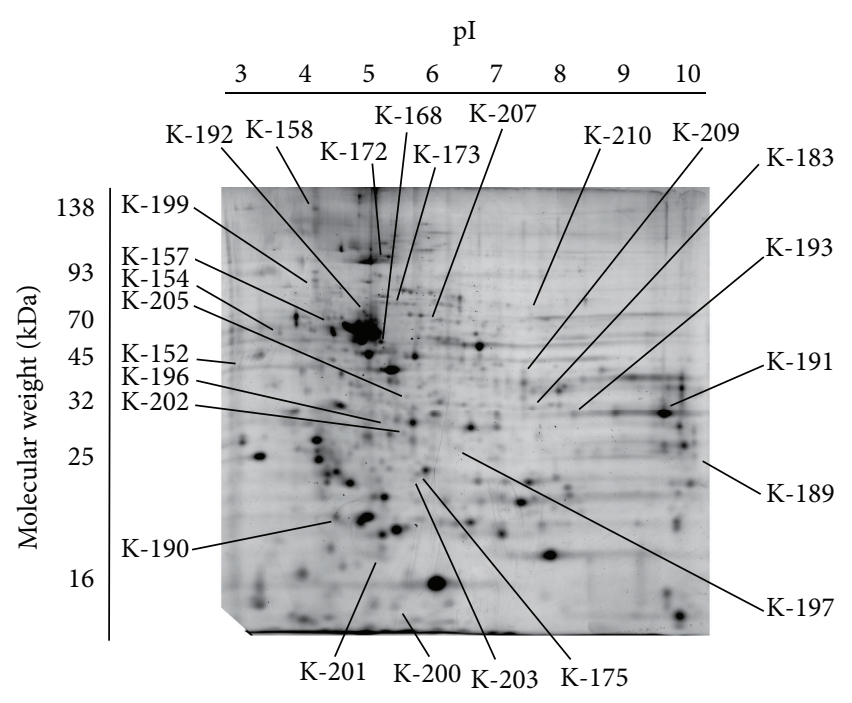

Figure 1: Photographs of a two-dimensional electrophoresis gel with annotation of the spots of identified proteins. The image shows a silver-stained gel of rat retina after TES. The proteins spots that were increased or decreased with or without TES that were identified by PMF are shown. Spots K-152 to K-210 represent the annotated spots. The $\mathrm{pH}$ gradient of the first dimension electrophoresis is shown at the top of the gels, and the migration of the molecular mass markers for SDS-PAGE in the second dimension is shown at the side of the gel. Representative gel images are shown.

control of the staining quality and matching of spots directly on the stained gels. In the end, twenty-five spots that had significant upregulation of volume were selected (Figure 1).

\subsection{Clustering of Identified Protein Spots. MALDI-TOF mass} spectrometry was performed to identify the twenty-five proteins. All of them were successfully identified with highquality spectra and probability scores of identification of $P<$ 0.05 .

Five of the 25 proteins, DLP-1, vimentin, angiopoietin-3, Elk, and ankyrin, were expressed only during the early phase, 30 minutes after the TES, while 10 proteins, immunoglobulin heavy chain 1a, SERPIN, calcineurin-2 regulator, Rasrelated GTP binding $\mathrm{B}, \mathrm{Ca}^{2+} / \mathrm{Mg}^{2+}$ ATPase, tenascin-X, EGF receptor, adenylate cyclase $10, \mathrm{TGF}-\beta$ regulator 4 , and dihydroxyacetone phosphate acryltransferase, were induced only in the latent phase. Others were expressed in both the acute and latent phases. These findings indicated that the effect of TES was still present 24 hours after stimulation and not just immediately after the stimulation (Table 1 ).

\section{Discussions}

Twenty-five proteins were differentially expressed in the retina of rats after TES, and their expression pattern was either early or latent after TES. TES after optic nerve transection in adult rats increased the number of surviving axotomized RGCs in vivo by increasing the level of insulin growth factor- (IGF-) 1 production by Muller cells [13]. An increase in brain-derived nerve growth factor (BDNF) expression at the mRNA and intracellular protein levels has been found in cultured Muller cells after TES [14]. TES also increased the expression of fibroblast growth factor- (FGF-) 2 [15]. However, neither IGF-1, BDNF, nor FGF-2 was upregulated in our proteomics results. This may be because our experimental model was different from previous ones in employing wild eyes without a crushed optic nerve.

The differentially expressed proteins included those involved in different kinds of cellular functions as follows. SIAH-2, adenylate cyclase $10, \mathrm{Ca}^{2+} / \mathrm{Mg}^{2+}$ ATPase, calciumbinding domain 1, DLP 1 , and calcineurin-2 regulator represent physiological factors identified as being differentially expressed. Nine cellular signaling molecules, GDI-2, angiopoietin-3, EGF receptor, Elk, Ras-GTP binding B, rhoGTPase activating protein, TGF- $\beta$ regulator 4 , prohibitin, and SERPIN, were identified. Three metabolic proteins were also identified, for example, HPPD, guanine nucleotide binding protein, and dihydroxyacetone phosphate acryltransferase. Two immunological proteins, HPPD and lymphocyte protein 1, and five structural proteins - vimentin, tenascin-X, VIF, keratin-8, and ankyrin-were upregulated by TES. These indicated that TES had effects on various kinds of cellular functions in the retina.

Among the identified proteins in this study, the pattern of protein expression was different at 30 minutes after TES and 24 hours after TES. While fifteen proteins were expressed at 30 minutes, 20 proteins were expressed at 24 hours, and, of these 20,10 had not been expressed at the acute phase. Sergeeva et al. mentioned that transcorneal alternating current stimulation induces EEG "after-effects" only in rats with an intact visual system but not after severe optic nerve damage [16]. The difference in our results indicated that TES induces acute and chronic changes in protein expressions. It is suspected that the acute change is a direct and transient effect induced by electric shock to neural cells while the chronic change is an indirect and secondary effect in mRNA expression or the protein signaling pathway.

We found that several neuronal synaptic agents were included among the identified proteins with an after-effect (i.e., appearing only at $24 \mathrm{~h}$, not at $30 \mathrm{~min}$ ). SIAH-2 (K183), a ubiquitin ligase enzyme, binds the major synaptic vesicle protein synaptophysin and facilitates its degradation by the ubiquitin-proteasome pathway [17]. GDI-2 (K-173) is associated with the plasticity of neurotransmission [18]. GDI2 is a signaling protein that regulates the GDP-GTP exchange reaction with members of the Rab proteins involved in vesicle transport. This process is critical for the release of synaptic vesicles [19]. These findings suggested that TES may have an effect on synaptic transmission in the retina to lead to upregulation in retinal function.

Proteins with chronic change or an "after-effect" are more important than proteins with acute change only, because ophthalmologists seek the stable upregulation of retinal function from the clinical use of TES. The identified proteins with chronic change included several proteins related to $\mathrm{Ca}^{2+}$ regulation. The regulator of calcineurin-2 (K-196) determines intracellular $\mathrm{Ca}^{2+}$ levels through the GABA-A receptor [20]. Calcium-binding and coiled coil domain 1 (K-154) is related 


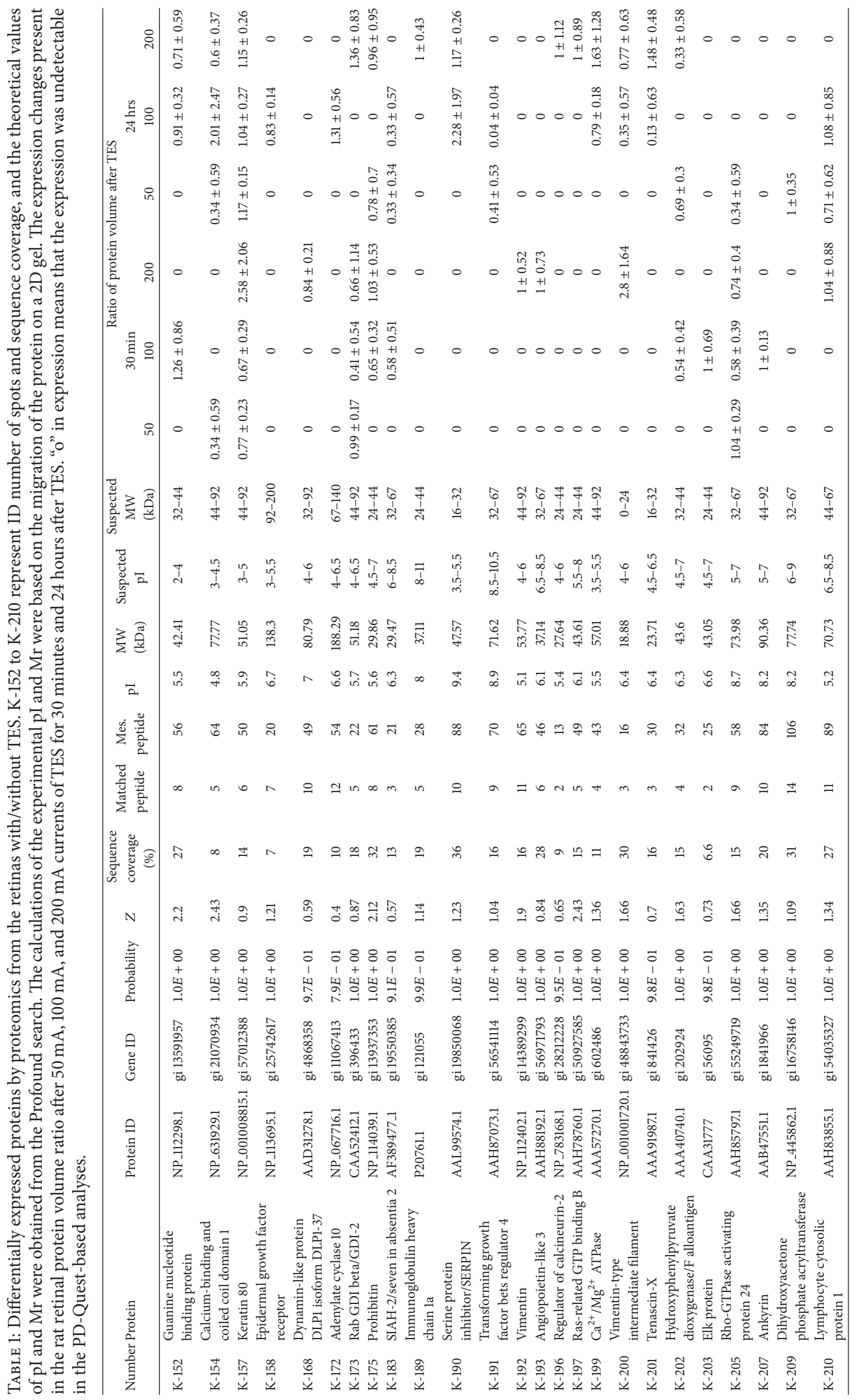


to $\mathrm{Ca}^{2+}$ regulation in mitochondria [21], and $\mathrm{Ca}^{2+} / \mathrm{Mg}^{2+}$ ATPase directly regulates intracellular $\mathrm{Ca}^{2+}$. These findings indicate that TES may affect intracellular $\mathrm{Ca}^{2+}$ regulation in retinal neural cells and increase retinal function.

Furthermore, some neuronal regenerative factors in aftereffect proteins were induced by TES. EGFR (K-158) regulates the axonal regeneration [22], and prohibitin (K-175) is also associated with axonal regeneration [23]. Transforming growth factor (TGF) regulator 4 is in the TGF-beta family and mediates the generation of the nervous system [24], and adenylate cyclase isoform (K-172) also regulates neural network wiring [25]. Tenascin-X (K-201) is associated with neuronal development [26] and is reexpressed in adults during normal processes such as nerve regeneration. It has also been stated that tenascin-X is present in the optic nerve and in peripheral nerves at the time of axonal growth [27]. Ras-related GTP binding B (K-197) and rho-GTPase activating protein $24(\mathrm{~K}-205)$ are also associated with dendritic regeneration [28]. Thus, EGFR, prohibitin, TGF regulator 4, adenylate cyclase isoform, tenascin-X, Ras-related GTP binding B, and rho-GTPase activating protein 24 are suspected to play roles in retinal regeneration after TES.

As known, a flicker light stimulation is often performed as one of the clinical examinations to stimulate the retina. The stimulation system in this study, electric stimulation with $20 \mathrm{~Hz}$, was different from a flicker $30 \mathrm{~Hz}$ light stimulation. Though $20 \mathrm{~Hz}$ was the best condition for neuroprotection in the retina $[5,11]$, we should check differences in protein expression changes for various conditions of TES, that is, frequencies, in a future study.

In conclusion, TES had effects on the expression of retinal proteins. These results will contribute to our knowledge on the mechanism of how TES affects the retina.

\section{Conflict of Interests}

The authors declare that there is no conflict of interests regarding the publication of this paper.

\section{References}

[1] N. M. Geremia, T. Gordon, T. M. Brushart, A. A. Al-Majed, and V. M. K. Verge, "Electrical stimulation promotes sensory neuron regeneration and growth-associated gene expression," Experimental Neurology, vol. 205, no. 2, pp. 347-359, 2007.

[2] A. A. Al-Majed, C. M. Neumann, T. M. Brushart, and T. Gordon, "Brief electrical stimulation promotes the speed and accuracy of motor axonal regeneration," Journal of Neuroscience, vol. 20, no. 7, pp. 2602-2608, 2000.

[3] T. Morimoto, T. Fujikado, J.-S. Choi et al., "Transcorneal electrical stimulation promotes the survival of photoreceptors and preserves retinal function in Royal College of Surgeons rats," Investigative Ophthalmology and Visual Science, vol. 48, no. 10, pp. 4725-4732, 2007.

[4] P. Henrich-Noack, N. Voigt, S. Prilloff, A. Fedorov, and B. A. Sabel, "Transcorneal electrical stimulation alters morphology and survival of retinal ganglion cells after optic nerve damage," Neuroscience Letters, vol. 543, pp. 1-6, 2013.
[5] T. Morimoto, H. Kanda, T. Miyoshi et al., "Characteristics of retinal reflectance changes induced by transcorneal electrical stimulation in cat eyes," PLoS ONE, vol. 9, no. 3, Article ID e92186, 2014.

[6] T. Fujikado, T. Morimoto, K. Matsushita, H. Shimojo, Y. Okawa, and Y. Tano, "Effect of transcorneal electrical stimulation in patients with nonarteritic ischemic optic neuropathy or traumatic optic neuropathy," Japanese Journal of Ophthalmology, vol. 50, no. 3, pp. 266-273, 2006.

[7] K. Inomata, K. Shinoda, H. Ohde et al., “Transcorneal electrical stimulation of retina to treat longstanding retinal artery occlusion," Graefe's Archive for Clinical and Experimental Ophthalmology, vol. 245, no. 12, pp. 1773-1780, 2007.

[8] S. Oono, T. Kurimoto, R. Kashimoto, Y. Tagami, N. Okamoto, and O. Mimura, "Transcorneal electrical stimulation improves visual function in eyes with branch retinal artery occlusion," Clinical Ophthalmology, vol. 5, no. 1, pp. 397-402, 2011.

[9] T. Morimoto, T. Fukui, K. Matsushita et al., "Evaluation of residual retinal function by pupillary constrictions and phosphenes using transcorneal electrical stimulation in patients with retinal degeneration," Graefe's Archive for Clinical and Experimental Ophthalmology, vol. 244, no. 10, pp. 1283-1292, 2006.

[10] N. Ozeki, K. Shinoda, H. Ohde, S. Ishida, and K. Tsubota, "Improvement of visual acuity after transcorneal electrical stimulation in case of Best vitelliform macular dystrophy," Graefe's Archive for Clinical and Experimental Ophthalmology, vol. 251, no. 7, pp. 1867-1870, 2013.

[11] T. Morimoto, T. Miyoshi, H. Sawai, and T. Fujikado, "Optimal parameters of transcorneal electrical stimulation (TES) to be neuroprotective of axotomized RGCs in adult rats," Experimental Eye Research, vol. 90, no. 2, pp. 285-291, 2010.

[12] T. Kanamoto, U. Hellman, C.-H. Heldin, and S. Souchelnytskyi, "Functional proteomics of transforming growth factor- $\beta 1$ stimulated Mv1Lu epithelial cells: Rad51 as a target of TGF $\beta 1$ dependent regulation of DNA repair," The EMBO Journal, vol. 21, no. 5, pp. 1219-1230, 2002.

[13] T. Morimoto, T. Miyoshi, S. Matsuda, Y. Tano, T. Fujikado, and Y. Fukuda, "Transcorneal electrical stimulation rescues axotomized retinal ganglion cells by activating endogenous retinal IGF-1 system," Investigative Ophthalmology and Visual Science, vol. 46, no. 6, pp. 2147-2155, 2005.

[14] T. Sato, T. Fujikado, T.-S. Lee, and Y. Tano, "Direct effect of electrical stimulation on induction of brain-derived neurotrophic factor from cultured retinal Müller cells," Investigative Ophthalmology and Visual Science, vol. 49, no. 10, pp. 46414646, 2008.

[15] T. Sato, T.-S. Lee, F. Takamatsu, and T. Fujikado, "Induction of fibroblast growth factor-2 by electrical stimulation in cultured retinal Mueller cells," NeuroReport, vol. 19, no. 16, pp. 1617-1621, 2008.

[16] E. G. Sergeeva, A. B. Fedorov, P. Henrich-Noack, and B. A. Sabel, "Transcorneal alternating current stimulation induces EEG 'aftereffects' only in rats with an intact visual system but not after severe optic nerve damage," Journal of Neurophysiology, vol. 108, no. 9, pp. 2494-2500, 2012.

[17] T. C. Wheeler, L.-S. Chin, Y. Li, F. L. Roudabush, and A. $\mathrm{Li}$, "Regulation of synaptophysin degradation by mammalian homologues of Seven in Absentia," Journal of Biological Chemistry, vol. 277, no. 12, pp. 10273-10282, 2002.

[18] H. Ishizaki, J. Miyoshi, H. Kamiya et al., "Role of Rab GDP dissociation inhibitor $\alpha$ in regulating plasticity of hippocampal neurotransmission," Proceedings of the National Academy of 
Sciences of the United States of America, vol. 97, no. 21, pp. 11587$11592,2000$.

[19] Y. Takai, T. Sasaki, and T. Matozaki, "Small GTP-binding proteins," Physiological Reviews, vol. 81, no. 1, pp. 153-208, 2001.

[20] R. Eckel, B. Szulc, M. C. Walker, and J. T. Kittler, "Activation of calcineurin underlies altered trafficking of $\alpha 2$ subunit containing $\mathrm{GABA}_{A}$ receptors during prolonged epileptiform activity," Neuropharmacology, vol. 88, pp. 82-90, 2015.

[21] M. Tominaga, H. Kurihara, S. Honda, G. Amakawa, T. Sakai, and Y. Tomooka, "Molecular characterization of mitocalcin, a novel mitochondrial $\mathrm{Ca}^{2+}$-binding protein with EF-hand and coiled-coil domains," Journal of Neurochemistry, vol. 96, no. 1, pp. 292-304, 2006.

[22] M.-F. Xu, H. Zhou, C.-Y. Hu, Y.-Q. Liang, L. Hu, and D. Chen, "The mechanisms of EGFR in the regulation of axon regeneration," Cell Biochemistry and Function, vol. 32, no. 1, pp. 101-105, 2014.

[23] B. T. Lang, J. Wang, A. R. Filous, N. P. B. Au, C. H. E. Ma, and Y. Shen, "Pleiotropic molecules in axon regeneration and neuroinflammation," Experimental Neurology, vol. 258, pp. 1723, 2014.

[24] F. C. Alcantara Gomes, V. de Oliveira Sousa, and L. Romão, "Emerging roles for TGF- $\beta 1$ in nervous system development," International Journal of Developmental Neuroscience, vol. 23, no. 5, pp. 413-424, 2005.

[25] X. Nicol and P. Gaspar, "Routes to cAMP: shaping neuronal connectivity with distinct adenylate cyclases," European Journal of Neuroscience, vol. 39, no. 11, pp. 1742-1751, 2014.

[26] F. S. Jones and P. L. Jones, “The tenascin family of ECM glycoproteins: structure, function, and regulation during embryonic development and tissue remodeling," Developmental Dynamics, vol. 218, no. 2, pp. 235-259, 2000.

[27] U. Bartsch, S. Bartsch, U. Dorries, and M. Schachner, "Immunohistological localization of tenascin in the developing and lesioned adult mouse optic nerve," European Journal of Neuroscience, vol. 4, no. 4, pp. 338-352, 1992.

[28] F. Raynaud, E. Moutin, S. Schmidt et al., "Rho-GTPaseactivating protein interacting with Cdc-42-interacting protein 4 homolog 2 (Rich2): a new Ras-related C3 botulinum toxin substrate 1 (Racl) GTPase-activating protein that controls dendritic spine morphogenesis," The Journal of Biological Chemistry, vol. 289, no. 5, pp. 2600-2609, 2014. 


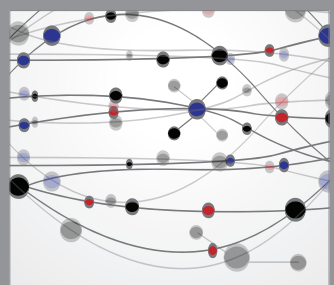

The Scientific World Journal
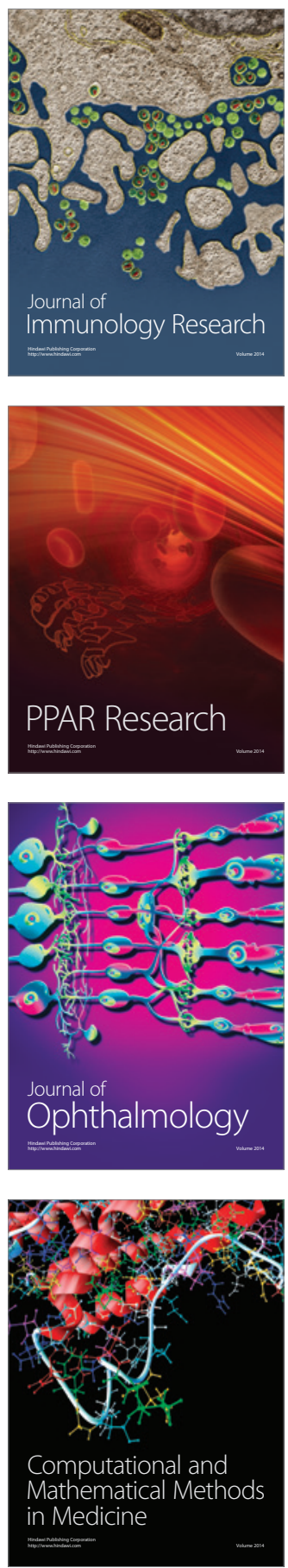

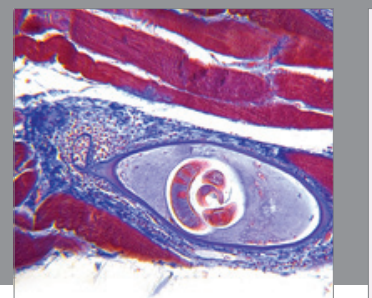

Gastroenterology

Research and Practice
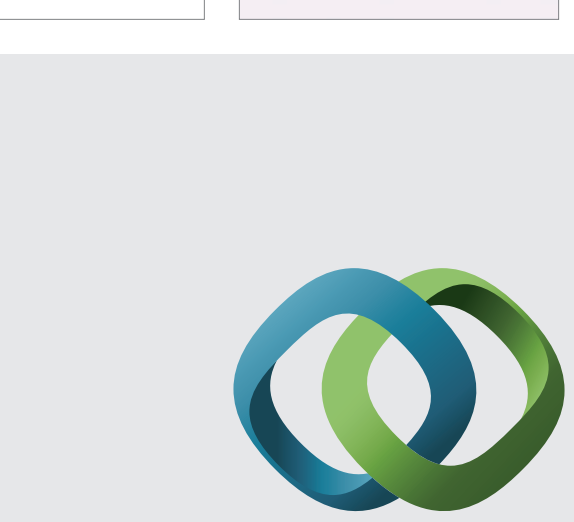

\section{Hindawi}

Submit your manuscripts at

http://www.hindawi.com
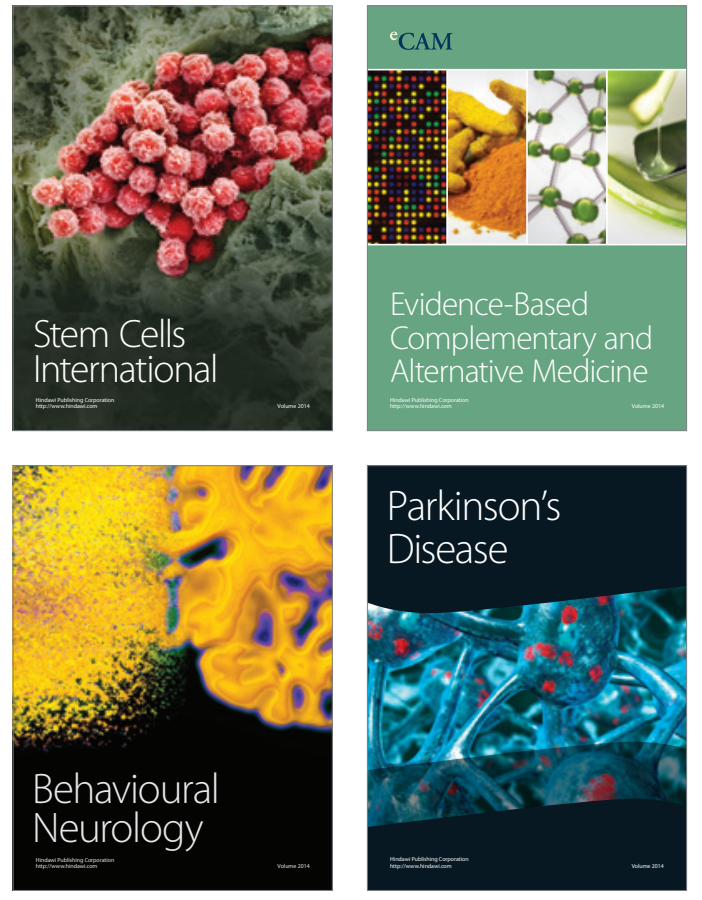
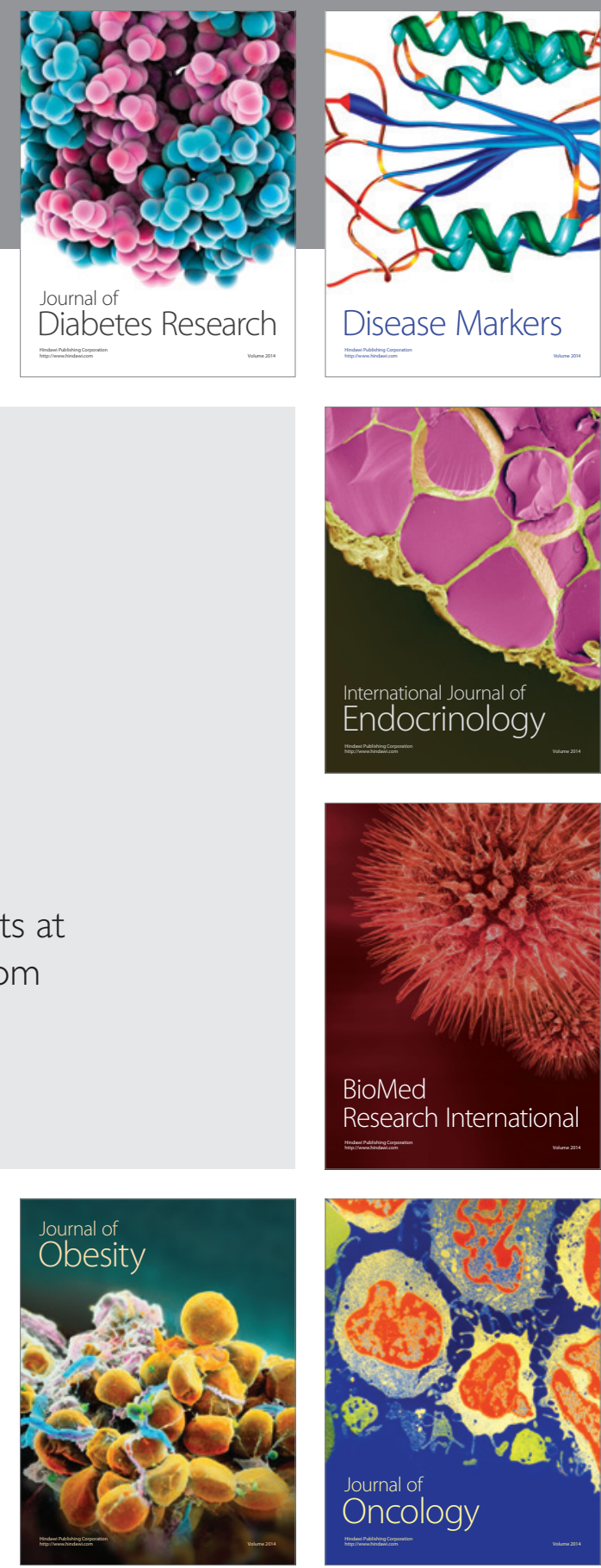

Disease Markers
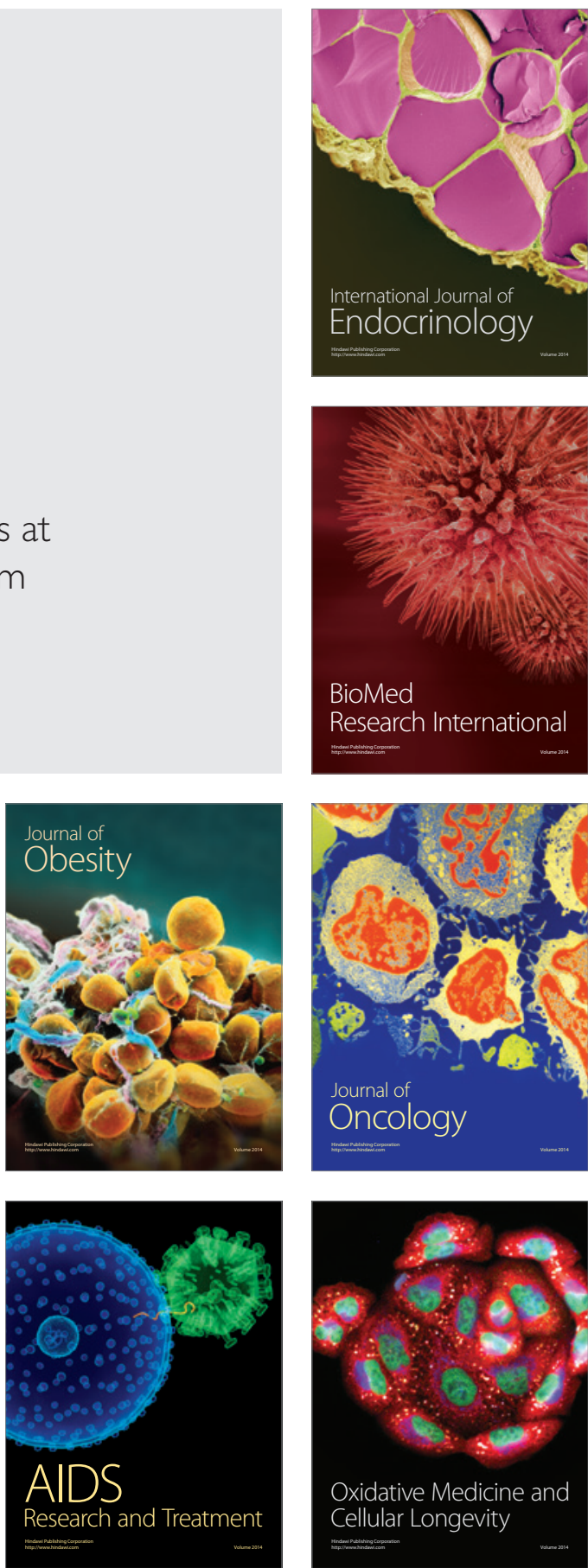